\title{
FONTES E CONTEXTO EUROPEO DA LINGÜÍSTICA SEGUNDO AMOR RUIBAL
}

\author{
Johannes Kabatek \\ Universität Tübingen
}

... porque sólo lo que es normal y reducible a sistema puede estudiarse científicamente

Ángel Amor Ruibal ${ }^{1}$

\section{INTRODUCIÓN}

Calquera persoa con interese pola historia da lingüística que entre por primeira vez en contacto coa obra lingüística de Amor Ruibal e vexa a súa enorme amplitude, a bibliografía manexada e a maneira aguda e crítica de argumentación, pensará que unha tal obra non pode proceder de alguén alleo aos centros de discusión lingüística da Europa do amencer do século XIX, ás escolas de Leipzig ou de París. Quen lea por primeira vez a Amor Ruibal preguntarase como é posible que fose preterida unha obra de semellante importancia. Dá a impresión de ser unha falsificación, unha fraude urdida por algún historiador de lingüística, xa que é dificilmente imaxinable que unha obra así puidese pasar inadvertida. É certo que a historia da lingüística, coma a historia de calquera disciplina e a historia en xeral (incompleta por definición), sempre pode darnos sorpresas e brindarnos descubertas inesperadas; pero, en xeral, cando se trata da lingüística occidental dos últimos séculos, supomos que as grandes liñas xa están ben trazadas e que os protagonistas xa son ben coñecidos. O que se descobre adoitan ser detalles, reaxustes ou, como moito, novas tramas que fan que o sabido apareza baixo outra luz. Nesta liña, foi un achado relativamente recente que o pontevedrés Fr. Martín Sarmiento (1695-1771) describira con notable acerto o funcionamento das leis fonéticas ${ }^{2}$, ou que o famoso gramático por-

1. PFFC II, p. 81.

2. Cf. J. Luis Pensado, Fray Martin Sarmiento. Sus ideas lingüísticas, Universidad de Oviedo, Oviedo 1960. 
tugués João de Barros (1496-1570) copiara por completo a súa gramática ${ }^{3}$ da de Antonio de Nebrija (1444-1522)4, ou que o reputado historiador do dereito Rafael Ureña y Smenjaud (1852-1930), contemporáneo de Amor Ruibal, presentara unha teoría do cambio lingüístico bastante moderna no seu Sumario de las lecciones de historia crítica de la literatura jurídica española 5 . O máis frecuente é que os descubrimentos sexan máis ben anecdóticos, coma o da figura do lingüista tubingués Karl Moritz Rapp (1803-1883) e a súa tipoloxía dos sons do mundo (unha teoría dalgún xeito emparentada coa chamada teoría da naturalidade, e incluso coa teoría da optimalidade, tan de moda hoxe). Nos seus escritos ${ }^{6}$, Rapp argüía que os sons das linguas do mundo corresponderían a unha xerarquía universal en que os ditongos nasais estarían nunha das escalas máis altas, polo cal consideraba que o portugués figuraba -a carón do seu dialecto materno de Rottweil ${ }^{7}-$ no nivel máis alto imaxinable.

Mais o caso de Amor Ruibal é totalmente distinto. Quero dicir xa de antemán, e sen esaxerar, que estamos ante un dos lingüistas máis importantes da historia de España, un lingüista digno de aparecer en todos os manuais de lingüística europea e que aínda nos ten reservada algunha que outra sorpresa, xa que algunhas das súas ideas teñen interese non só para a historiografía, senón tamén para a actualidade.

3. J. de Barros, Grammatica da lingua portuguesa, apud Lodovicum Rotorigium, Lisboa, 1540 .

4. A. de Nebrija, Gramática castellana, [s. n.], Salamanca, 1492.

5. R. Ureña y Smenjaud, Sumario de las lecciones de historia crítica de la literatura jurídica española, dadas en la Universidad Central, durante el curso de 1897 a 98, Imprenta de la Revista de Legislación, Madrid, 1898, pp. 349-393.

6. K. M. Rapp, Versuch einer Physiologie der Sprache nebst historischer Entwicklung der abendländischen Idiome nach physiologischen Grundsätzen, Cotta, Stuttgart, 4 vols., 1836-1841; K. M. Rapp, Grundriß der Grammatik des indisch-europäischen Sprachstammes, Cotta, Stuttgart, 6 vols., 1852-1859.

7. Rottweil é unha pequena cidade (ten arestora 25000 habitantes, aproximadamente), sita no corazón de Baden-Württemberg, a uns 60 kilómetros ao sur de Tübingen, e non lonxe das fronteiras suíza e francesa (fican a uns 60 kilómetros ao sur e a uns 100 kilómetros ao oeste do lugar, respectivamente). 


\section{UNIDADE DA OBRA}

O tema que se abordará nas seguintes páxinas, isto é, as fontes e o contexto europeo da obra de Amor Ruibal, é relativamente doado de tratar (en comparación coa complexa cuestión da súa influencia en España), grazas a que o propio don Ángel nos informou detalladamente das súas lecturas, e a que coñecemos o contido da súa biblioteca ${ }^{8}$. A historia da recepción dos seus traballos, en cambio, é moito máis complexa, xa que hai que resolver a cuestión de se realmente foi tan limitada como parece, ou se, pola contra, se deu unha recepción somerxida, non explícita pero si presente. Pero haberá que deixar esoutro tema para os especialistas en historiografía lingüística hispánica.

Abordaremos aquí a obra lingüística amorruibaliana en conxunto, mais centrándonos na máis importante das súas achegas á ciencia da linguaxe: Los problemas fundamentales de la filología comparada ${ }^{9}$. Non resulta fácil establecer unha clara cronoloxía do pensamento de Amor Ruibal, agás cando se refire a escritos doutros lingüistas que se publicaron ao longo dos dous ou tres primeiros anos do século xx (o ano de publicación indica que os argumentos de Amor Ruibal ao respecto non poden ser anteriores). Aínda así, quero sinalar que parece que Amor Ruibal dispoñía xa a finais do século XIX dunha formación moi sólida na lingüística da época, o

8. S. Casas Blanco, «El catálogo de la biblioteca de don Ángel Amor Ruibal», Pensamiento, XXV/100, 1969, pp. 371-402; «El catálogo de la biblioteca de don Ángel Amor Ruibal (continuación)», Pensamiento, XXVI/101, 1970, pp. 33-71; «Problemas bibliográficos de Amor Ruibal», en VV. AA., Angel Amor Ruibal en la actualidad, CSIC: Instituto de Filosofía Luis Vives, Madrid, 1973, pp. 3-80. A continua preocupación de don Ángel pola actualidade bibliográfica percibímola tamén nas numerosas misivas que dirixiu a libreiros de Francia, Alemaña, Austria, etc., e que aínda se conservan. Aproveito a ocasión para agradecerlle a Andrés Torres Queiruga que tivese a xentileza de me facilitar copias da correspondencia de Amor Ruibal.

9. Á. Amor Ruibal, Los problemas fundamentales de la filología comparada. Su historia, su naturaleza y sus diversas relaciones científicas. Primera Parte, Consello da Cultura Galega, Santiago de Compostela, 2005 [princeps, 1904]; Á. Amor Ruibal, Los problemas fundamentales de la filología comparada. Su historia, su naturaleza y sus diversas relaciones científicas. Segunda Parte, Consello da Cultura Galega, Santiago de Compostela, 2005 [princeps, 1905]. 
que se reflicte na disposición do seu Programa de lenguas bíblicas con principios de gramática comparada ${ }^{10}$. Noutras palabras: con menos de trinta anos, don Ángel xa dispuña dos coñecementos de lingüística que lle ían servir de fundamento para o seu labor científico ulterior; formación adquirida nesa insularidade da que falara José Filgueira Valverde (1906-1996) ${ }^{11}$. Ademais, se aceptamos que hai un continuum entre dous tipos de científicos opostos, os que modifican a súa concepción teórica repetidas veces ao longo da súa vida e os que se manteñen fieis a un pensamento inicial, Amor Ruibal sitúase claramente no segundo extremo, cunha concepción fundamental que cambia pouco ao longo da súa vida e que reaparece na súa obra filosófica e teolóxica, profundamente marcada polo pensamento lingüístico dos anos de xuventude. Clara mostra desa continuidade é a frecuencia con que Amor Ruibal copia ao pé da letra pasaxes da súa primeira obra exhaustiva de lingüística ${ }^{12}$, non por falta de ideas novas, senón porque -como é de supoñer- aínda subscribía nas obras posteriores o que escribira con anterioridade.

Para demostrar de que modo manexa as fontes Amor Ruibal e como fía argumentos na súa obra, imos facer, a modo de exemplo, catro calas en senllos temas centrais da lingüística xeral dos últimos anos do século xIx e os primeiros do xx: o debate sobre a índole abstracta da lingua en contraposición co falar, que é a realidade lingüística primaria; o carácter do falar como actividade en que a lingua se manifesta e, así mesmo, é re-creada; a relación entre fala e escrita; e, por ultimo, a recepción e interpretación do herdo

10. Á. Amor Ruibal, Programa de lenguas bíblicas con principios de gramática comparada. Estudios superiores, Seminario Conciliar Central, Santiago de Compostela, 1898.

11. Filgueira Valverde presenta a don Ángel como «un erudito aislado en una tierra aislada» («Amor Ruibal en la cultura gallega de su tiempo», en VV. AA., Ángel Amor Ruibal..., op. cit., pp. 537-554).

12. P. Regnaud, Principios generales de lingüística indo-europea. Versión española, precedida de un estudio sobre la ciencia del lenguaje por el Dr. Á. Amor Ruibal, Consello da Cultura Galega, Santiago de Compostela, 2005 [princeps, 1900]. Non estará de máis sinalar que a «Introducción» de don Ángel enche cento trinta e catro páxinas, mentres que a tradución do orixinal francés (Principes généraux de linguistique indo-européenne publiés à l'usage des candidats aux agrégations de philosophie et de grammaire, Hachette, París, 1890) ocupa só cincuenta e dúas. 
dos mestres Franz Bopp (1791-1867) e Wilhelm von Humboldt (1767-1835). Poderiamos elixir outros temas, pois, no fondo, en calquera tema pode apreciarse a singular maneira de traballar de Amor Ruibal, coherente e homoxénea.

\section{A CUESTIÓN DA LINGUA COMA ABSTRACCIÓN}

Un problema moi discutido na lingüística do século xx -e ata a actualidade-é o da problemática da abstracción do signo lingüístico e das categorías lingüísticas en xeral. Nos últimos anos vénse afirmando, sobre todo desde as posicións da lingüística cognitiva, que a noción estruturalista de lingua -no sentido de Ferdinand de Saussure (1857-1913) - non se corresponde coa realidade lingüística. O estruturalismo considérase superado e a concepción da lingua como un sistema abstracto contémplase como un invento dos lingüistas, como unha creación artificial da ciencia, divorciada da realidade primaria da linguaxe, da actividade dos suxeitos falantes. Dise que a visión da estrutura lingüística como algo hermético e pechado é incompatible coas novas teorías, que xulgan caduca a noción aristotélica das categorías como unidades discretas, nidiamente separadas unhas das outras. En troques, prefírese partir dunha noción fluída das categorías, con núcleos prototípicos e bordes imprecisos. Nós non podemos entrar aquí en detalles do debate actual, pero queremos sinalar que a negación das categorías (no sentido aristotélico) e a súa substitución polos conceptos cognitivos de fluidez son un grande erro, atribuíble a unha das confusións máis antigas no eido da filosofía da linguaxe: non facer distinción entre os distintos niveis do pensamento categorial no sentido aristotélico (necesario para a clasificación abstracta dos obxectos da nosa percepción, incluso para o recoñecemento de realidades fluídas), e a percepción mesma desas realidades (que, evidentemente, non é categorial de antemán). Polo tanto, se partimos da existencia destes dous niveis, existen dúas modalidades posibles de reducionismo: ou negar o nivel categorial abstracto ou negar o nivel da percepción, no cal están situados os posibles efectos de continuo e de prototipicidade. Os protagonistas da redución cognitivista repróchanlle precisamente ao estruturalis- 
mo (incluída a gramática xerativa, que se considera prolongación do pensamento estruturalista) a redución á abstracción. E como teñen por presuposto a inexistencia de categorías no sentido aristotélico e a inexistencia dun nivel de abstracción de unidades discretas, chegan á conclusión de que os que si supoñen a súa existencia están a crer en algo inventado polos lingüistas, inexistente para os falantes. Saussure, consciente destes problemas, insistía no carácter concreto da lingua. A esencia do signo lingüístico é precisamente esa coexistencia de niveis, de abstracción por un lado (pero unha abstracción que como entidade psíquica ten existencia concreta para os seres categorizantes) e aplicable ao concreto polo outro lado e noutro nivel:

La langue n'est pas moins que la parole un objet de nature concrète, et c'est un grand avantage pour l'étude. Les signes linguistiques, pour être essentiellement psychiques, ne sont pas des abstractions; les associations ratifiées par le consentement collectif, et dont l'ensemble constitue la langue, sont des réalités qui ont leur siège dans le cerveau ${ }^{13}$.

Saussure insiste neste tema porque a principios do século XX se debatía en Leipzig e en París sobre a cuestión da abstracción na ciencia da linguaxe. A postura extrema de negarlle toda base real á abstracción atopámola nas Antinomies linguistiques ${ }^{14}$ de Victor Henry (1850-1907), que Amor Ruibal cita e discute amplamente. O primeiro capítulo das Antinomies, que está estruturado (ao igual que os dous restantes) arredor dunha «thèse» e dunha «antithèse», comeza así:

Thèse

La catégorie du langage, celle de la langue et du dialecte, celle même du simple mot, pour peu qu'on y regarde de près, ne sont que des abstractions sans réalité extérieure.

Antithèse

13. F. de Saussure, Cours de linguistique générale, Payot, París, 1972 [1ª edición, 1916], p. 32 .

14. V. Henry, Antinomies linguistiques[. Le langage martien], Lovaina, Peeters, 2001 [princeps, 1896]. 
Il existe une science du langage, qui se propose pour objet l'étude des phénomènes de la vie du langage, c'est-à-dire de la vie des langues et de la vie des mots ${ }^{15}$.

Discusión que Henry resolve nos seguintes termos:

Le langage, soit désignant la faculté générale de parler, ou l'exercice de cette faculté, - respectivement ce que les grecs nommaient

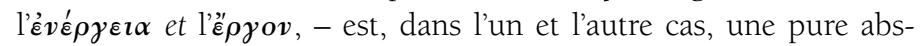
traction sans réalité extérieure ${ }^{16}$.

Achamos na obra de Henry un xogo retórico (Amor Ruibal caracterizará o seu xeito de expresarse como «más elegante que precis $[0] »^{17}$ ) que se funda en presupostos falsos e invoca a tradición de maneira errada ${ }^{18}$. Don Ángel, antes ca Saussure, analiza as propostas de Henry no contexto das controversias dos neogramáticos acerca da licitude ou ilicitude de expresións metafóricas como vida da linguaxe e similares e aproveita a ocasión para deixar establecidos algúns principios fundamentais de epistemoloxía. Xa cando presenta a obra de Henry, Amor Ruibal non tarda en dicir palabras ben claras de rexeitamento: «[E]xaminemos -escribe o noso autor ${ }^{19}$ algunos de los sofismas glotológicos que V. Henry acumula en su reciente trabajo "Antinonies [sic] lingüistiques", compuesto con el criterio más exclusivista posible en un partidario de la escuela de Brugmann». Amor Ruibal cita a tese de Henry sobre a cuestión da abstracción, tradúcea ao castelán, e comenta decontado:

Que las categorías señaladas sean abstracciones (con más propiedad dijéranse obtenidas por abstracción) es cosa harto conocida de todo el que no se imagine la unidad absoluta de los géneros y

15. V. Henry, Antinomies..., op. cit., p. 5.

16. V. Henry, Antinomies..., op. cit., p. 24.

17. PFFC II, p. $122 \mathrm{n}$.

18. Como se comproba, por exemplo, no uso que fai dos termos humboldtiano-aristotélicos de èvé Henry dá a entender.

19. PFFC II, p. 108. 
especies como un tipo objetivo de realidad subsistente genérica o específica. Pero que a las abstracciones no corresponda realidad alguna exterior, sólo puede afirmarse negando la objetividad de nuestros conceptos, y con ello la realidad de toda noción científica propiamente $\mathrm{tal}^{20}$.

Segue un parágrafo en que Ruibal relaciona o malentendido coa vella oposición entre realismo e nominalismo, ata chegar á mesma conclusión de Saussure, pero incluso de maneira máis argumentada e máis fundamentada, cando di:

En las aludidas escuelas filosóficas la falsedad de sus asertos provino de pretender que el entendimiento se ajustase exclusivamente a las cosas, sin que también las cosas se ajustasen al entendimiento; esto es, se le daba a la inteligencia el elemento material en los singulares y se le negaba al mismo tiempo todo derecho al elemento formal, o sea su facultad privativa de ver en ellos las cualidades comunes reducibles por lo mismo a la unidad de la idea, sin quebrantar la singularidad de la cosa, que es justamente la obra de abstracción y el germen de toda ciencia. Y esto con toda exactitud acontece en las dos tendencias glotológicas mencionadas, de las cuales una convierte en realidades las abstracciones como tales, y otra niega que las abstracciones tengan su fundamento propio en las realidades. Contra unos y otros la Glotología, como toda ciencia, debe legitimar y legitima la verdad de las categorías abstractas en cuanto son tomadas de la realidad de los seres concretos, y de la verdad que se predica de los seres concretos en cuanto entendidos por ideas abstractas. Las expresiones, pues, lengua, lenguaje etc., son abstractas, por lo mismo que tienen una realidad concreta en los sonidos, sobre cuyo conjunto recaen; pues de otra suerte no serían abstractas, sino simplemente falsas ${ }^{21}$.

As palabras de Amor Ruibal superan as do Cours de Saussure tanto pola súa claridade como pola referencia concreta ás fontes da tradición grega. Evidentemente, Amor Ruibal escribe un tratado e Saussure, en troques, dá unha clase; e non sabemos tam-

20. PFFC II, p. 108.

21. PFFC II, p. 109. 
pouco ata que punto na obra de Saussure están perdidas as mencións das fontes. Pero non deixa de sorprender o nidio da argumentación de don Ángel e a forza de superioridade con que, desde a súa provincia remota, lle dá unha lección a un coñecido lingüista da Sorbona ${ }^{22}$. É a súa unha superioridade xustificada desde a formación filosófica e o coñecemento da doutrina aristotélica, que lle permite empregar palabras coma cousas, abstracción, realidade, obxectos, concreto, etc. non de maneira inxenua e tomándoas da lingua cotiá, senón como termos pertencentes a un sistema filosófico compartido cunha liña de tradición desde a antigüidade. Isto tamén se ve na concepción mesma da actividade do falar, como se verá no próximo apartado.

\section{4 'Evépyєı e ěpyov}

É un feito coñecido que ata a época dos neogramáticos era común, especialmente entre os neogramáticos mesmos, referirse á distinción humboldtiana entre linguaxe como évé $\rho \gamma \varepsilon \imath \alpha$, por unha parte, e linguaxe como ếpgov, por outra parte ${ }^{23}$. Humboldt fala de Tätigkeit ('actividade') en oposición a Werk ('produto [scil. do falar]', insistindo en que a esencia da linguaxe está na actividade e afirmando que a linguaxe é real unicamente na actividade de falar:

Die Sprache, in ihrem wirklichen Wesen aufgefasst, ist etwas beständig und in jedem Augenblicke Vorübergehendes. Selbst ihre Erhaltung durch die Schrift ist immer nur eine unvollständige, mumienartige Aufbewahrung, die es doch erst wieder bedarf, dass

22. Contra a fin de 1888, a raíz da prematura morte de Abel Bergaigne (1838-1888), encomendóuselle a Victor Henry a docencia de gramática comparada na Faculté des Lettres de París, ficando a de lingua sánscrita (a segunda das dúas materias que impartía Bergaigne) nas mans de Sylvain Lévi (1863-1935). Posteriormente, Lévi foi chamado ao Collège de France, de tal xeito que Henry asumiu tamén os cursos de sánscrito, e foi nomeado "professeur titulaire de sanskrit et grammaire comparée» (cf. A. Meillet, «Victor Henry», Bulletin de la Société de Linguistique de Paris, XIV/55, 1907, p. CCXXVII).

23. W. von Humboldt, Gesammelte Schriften, hrsg. von der koeniglich preussischen Akademie der Wissenschaften. Bd. 7, Hälft.1. Einleitung zum Kawiwerk, Behr, Berlín, 1907 , pp. 45 ss. 
man dabei den lebendigen Vortrag zu versinnlichen sucht. Sie selbst ist kein Werk (Ergon), sondern eine Thätigkeit (Energeia) ${ }^{24}$.

Pasaxe que Amor Ruibal -que admiraba a Humboldt, pero non cega nin incondicionalmente ${ }^{25}$ - parafrasea desta forma:

La lengua considerada en su realidad objetiva concreta psicofísica (idea asociada a un sonido) es una actividad, -una energía- exteriorizada que no existe sino en los individuos al proferir las palabras singulares de que aquella se compone, y que deja de existir en el momento mismo en que estas desaparecen ${ }^{26}$.

As pegadas de Humboldt están continuamente presentes en toda a obra lingüística de don Ángel. De feito, o pensamento humboldtiano abordábase xa nun dos temas no Programa de lenguas bíblicas con principios de gramática comparada segundo o cal organizara o noso autor as súas leccións de idiomas orientais na Universidade Pontificia composteláa ${ }^{7}$. Tamén establece o vínculo

24. W. von Humboldt, Gesammelte Schriften..., op. cit., pp. 45-46.

25. Cf., por exemplo, o seu xuízo sobre o papel de Humboldt no nacemento dos estudos de gramática comparada das linguas indoeuropeas: «El eminente Guillermo [de] Humboldt, de quien se reconoce discípulo Bopp, y a cuya memoria consagra sentidas frases, no puede en rigor llamarse maestro de éste en materia de Gramática comparada, sino de una manera general, en el mismo sentido en que Pott, Schleicher[,] etc., se declaran sus discípulos. Humboldt ha ejercido indiscutible ascendiente sobre los filólogos de su tiempo, más por saber universal y por su protección decidida a las letras que por sus investigaciones propias en la familia indoueuropea, ni por sus teorías en este punto» (PFFC II, p. 45).

26. PFFC II, pp. 102-103.

27. Acerca das circunstancias do nacemento da Universidade Pontificia de Santiago de Compostela, cabe citar o testemuño do Cardeal Arcebispo de Santiago, Mons. José María Martín de Herrera y de la Iglesia (1835-1922), nunha carta pastoral de setembro de 1897 (Boletín Oficial del Arzobispado de Santiago de Compostela, 1480, 20 de setembro de 1897, pp. 441-442) «La feliz coincidencia del corriente Año Santo con la canónica erección de las facultades de Filosofía, Sagrada Teología y Derecho Canónico en nuestro Seminario Conciliar de Compostela, nos impulsa a dirigiros esta carta pastoral para demostrar el júbilo que ha producido en nuestro corazón tan fausto suceso. El Decreto Pontificio del 15 de Febrero último ha elevado el Seminario Compostelano a la categoría de Universidad Eclesiastica, continuando así y perfeccionando el 
entre a concepción humboldtiana da linguaxe e a súa adaptación por parte dos neogramáticos: «Humboldt reconocía el carácter psíquico de la palabra, y a él recurren los neogramáticos al sostener su teoría de la lengua como una energueia $[$ sic $] \gg^{28}$.

Xa vimos como na discusión das teses de Victor Henry afloraban tamén os dous termos aristotélico-humboldtianos ${ }^{29}$. En xeral, cabe dicir que se achan entre os máis citados ao longo dos últimos douscentos anos da historia da lingüística. Só se marxinalizaron despois da introdución das dicotomías langue/parole de Saussure ou competence/performance de Noam Chomsky, e, así e todo, tiveron continuidade e recuperación nalgunhas escolas lingüísticas do século xx. É interesante observar, porén, que en moitos traballos de lingüística estes termos se citan a modo de referencia prestixiosa nas

Pontificie reinante [León XIII Papa, 1878-1903] la obra de su predecesor el inmortal Pío IX [Papa, 1846-1878]» (apud J. L. Lemos Montanet, "Obra viva» de Ángel Amor Ruibal, CSIC: Instituto Padre Sarmiento de Estudios Gallegos, Santiago de Compostela, 2004, p. 158). Con motivo da transformación en Universidade, creouse unha cátedra de «Lenguas Orientales» que Amor Ruibal ocupou desde o primeiro día (cf. J. L. Lemos Montanet, «Obra viva»..., op. cit., p. 166).

28. PFFC II, p. 104.

29. A distinción entre évé $\rho \gamma \varepsilon \imath$ e ěpyov aparece, por exemplo, no comezo da Ética a Nicómaco: «Toda arte y toda investigación, y del mismo modo toda acción y elección, parecen tender a algún bien; por esto se ha dicho con razón que el bien es aquello a que todas las cosas tienden. Pero parece que hay alguna diferencia entre los fines, pues unos son activi-

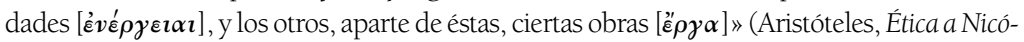
maco [edición bilingüe e tradución por M. Araújo e J. Marías], Instituto de Estudios Políticos, Madrid, 1959, p. 1). E tamén, por suposto, na Metafísica: «Y puesto que lo último de algunas potencias es el uso (por ejemplo, lo último de la vista es la visión, y, fuera de ésta, ninguna otra obra se produce a base de la vista), pero a base de algunas potencias sí se produce algo (por ejemplo, a base del arte de edificar, además de la edificación, se produce una casa),

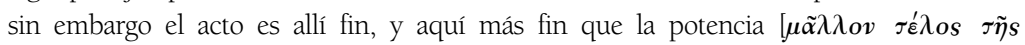
$\left.\delta v v \alpha \dot{\mu} \mu \varepsilon \omega_{s}\right]$; pues la edificación está en lo que se edifica, y se produce y es simultánea con la casa. Pero cuando las potencias tienen como resultado alguna cosa además del uso, su acto [ẻvépgeı $\alpha$ ] está en lo que se hace (por ejemplo, la edificación en lo que se edifica, y la acción de tejer, en lo que se teje, y de modo semejante en las demás cosas, y, en general, el movimiento en lo que se mueve); pero cuando no tienen ninguna otra obra [हैeyov] sino el acto

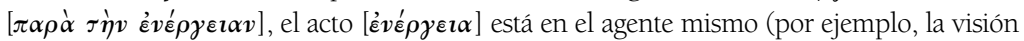
en el que ve, la especulación en el que especula y la vida en el alma [...])» (Aristóteles, Metafisica [edición trilingüe por V. García Yebra], Gredos, Madrid, 1970, vol. 2, pp. 64-65). 
introducións conceptuais, sen que posteriormente se preste atención ás ensinanzas que encerran. Así, por exemplo, polo que atangue ás teorías do cambio lingüístico, é bastante frecuente que a cuestión do cambio se presente a un nivel abstracto, preguntándose por que cambia a lingua, no canto de se preguntar como a actividade do falar (creativa por definición) fai que, ao comparar un épgov con outro, se dea a impresión de cambio ${ }^{30}$.

Amor Ruibal, a diferenza de moitos outros estudosos, non cita os termos como adorno para pasar despois da mención á descrición de produtos sen ter en conta a actividade. El busca a verdadeira comprensión, que o conduce incluso máis alá da simple cita, ata unha discusión e unha definición do signo lingüístico e da linguaxe. Debate varias propostas de definición e vainas rexeitando para achegarse a outra, máis exacta; acerca da parella évé $\rho \boldsymbol{\gamma} \varepsilon \imath \boldsymbol{\alpha} e$ ếrov, Amor Ruibal di o seguinte:

El doble carácter que es dado distinguir en la palabra en cuanto es individualmente una évé $\rho \gamma \varepsilon \imath \boldsymbol{\alpha}$ y en cuanto socialmente podemos considerarla como un ếpyov; o sea, su doble aspecto en cuanto la lengua es formación directa individual y peculiar al que habla, y en cuanto es obra social reflejadamente llegada a nosotros, que la tomamos del medio ambiente en que física e intelectualmente nos

30. Isto é común en toda unha longa tradición de traballos sobre cambio lingüístico. Nos últimos anos, unha das teorías que con máis claridade postula investigar o cambio no nivel abstracto é a chamada teoría da man invisible do alemán Rudi Keller (Sprachwandel. Von der unsichtbaren Hand in der Sprache, Francke, Tubinga, $2003^{3}$ [1ª edición, 1990]). Keller compara o proceso do cambio lingüístico coa formación dunha verea do campus da súa universidade, creada inconscientemente polos estudantes que querían atravesar o céspede por un atallo. A métafora non é mala, posto que, na linguaxe, a finalidade comunicativa pode crear indirectamente medios novos que non correspondían á finalidade inicial. Con todo, cómpre ter presente que as vereas nunca son creadas por mans invisibles, senón xeralmente por pés visibles (cf. J. Kabatek, «Über Trampelpfade, sichtbare Hände und Sprachwandelprozesse», en Thomas Stehl, ed., Unsichtbare Hand und Sprecherwahl. Typologie und Prozesse des Sprachwandels in der Romania, Narr, Tubinga, 2005, pp. 155-174).

A carón dos traballos que expresamente postulan a investigación do cambio no nivel abstracto, hai tamén outros que polo menos citan a modo de preámbulo a distinción humboldtiana e subliñan a importancia de considerar a linguaxe como évé $\rho \gamma \varepsilon \imath \alpha . .$. mais pasan decontado a unha descrición independente da actividade do falar. 
formamos, hace que la noción de lenguaje pueda presentarse desde diversos puntos de vista, ofreciéndose una misma definición de vario modo según se considere la lengua como producida en cada uno, o como recibida ya de los que la poseen cual instrumento social ${ }^{31}$.

A diferenza de Saussure, que fixo seu o concepto de «fait social» do sociólogo Émile Durkheim (1858-1917)32, adaptándoo ao pensamento lingüístico), Ruibal recoñeceu o carácter social da lingua sen deixar de insistir na creatividade da évépgeı $\alpha$. Vemos, pois, un intento de ampliar a concepción humboldtiana e de incluír nela unha segunda cuestión, a da relación entre individuo e sociedade.

Anos máis tarde, o gran psicólogo e lingüista Karl Bühler (1879-1963) establecería na súa Sprachtheorie ${ }^{33}$ unha distinción que permitía combinar a terminoloxía de Humboldt (Tätigkeit fronte a Werk, isto é, actividade fronte a produto) coa de Saussure (parole fronte a langue, isto é, acto individual fronte a feito social). Di Bühler que nin os termos de Humboltd nin os de Saussure foron verdadeiramente fértiles no mundo da lingüística, e que, para facelos realmente aproveitables, habería que combinar as distincións correspondentes: «[W]eder das alte noch nas neue Paar ist richtig produktiv geworden im Reich der sprachwissenschaftlichen Grundbegriffe» ${ }^{34}$. Bühler distingue, polo tanto, entre dous planos diferentes de consideración da actividade lingüística e establece a partir de aí o seu coñecido quadrifolium:

\begin{tabular}{|l|l|l|}
\hline & I & II \\
\hline 1. & H & W \\
\hline 2. & A & G \\
\hline
\end{tabular}

31. PPFC II, p. 121.

32. Cf. É Durkheim, Les règles de la méthode sociologique, Alcan, París, 1895, pp. 5-19

33. K. Bühler, Sprachtheorie. Die Darstellungsfunktion der Sprache, Gustav Fischer, Iena, 1934.

34. Cf. K. Bühler, Sprachtheorie. Die..., op. cit., p. 48. 
Segundo Bühler, cómpre considerar os fenómenos lingüísticos nos seus catro aspectos («Seiten») ou momentos («Momente») ${ }^{35}$. En primeiro lugar, cabe clasificalos como fenómenos relacionados cos suxeitos (I) ou independentes dos suxeitos (II). En segundo lugar, pódense distinguir dous graos diferentes de formalización: un primeiro grao (1), baixo, de accións ( $H$, inicial do al. Handlungen) e obras (W, inicial do al. Werke); un segundo grao (2), alto, de actos (A, inicial do al. Akte) e creacións ( $G$, inicial do al. Gebilde ${ }^{36}$ ). Xa que logo, no quadrifolium resultante recóllense, de forma combinada -e cruzada-, as dúas dicotomías. Un fenómeno relacionado co suxeito e de baixo grao de formalización sería a parole de Saussure, é dicir, a realización individual da langue, que, considerada de maneira independente do suxeito (como resultado exteriorizado), é un Werk, ou ếpyov. No segundo nivel, de máis alta formalización (ou, mellor dito, desde o funcionamento interno), a actividade consiste na évé $\rho y \varepsilon \imath \alpha$ concibida como actos individuais, os cales, nun nivel máis alto, chegan a establecer un Gebilde, isto é, un conxunto de elementos que forman un sistema funcional ou langue ${ }^{37}$.

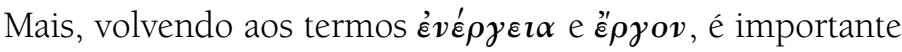
sinalar que tradicional e comunmente se atribúen a Aristóteles - de feito, así fan os neogramáticos e outros lingüistas dos séculos XIX e XX-; inda que, en xeral, se toman de Humboldt sen buscar a súa verdadeira raíz aristotélica ${ }^{38}$. No canto de seguir citando a distinción aristotélica a través de Humboldt, Eugenio Coseriu (1921-2002) propuxo nos anos 50 do pasado século a volta á terminoloxía orixinal. En «Determinación y entorno ${ }^{39}$, Coseriu cita as distincións

35. K. Bühler, Sprachtheorie. Die..., op. cit., p. 48.

36. Nótese, porén, que Javier Marías (1914-2005), responsable da versión española da Sprachtheorie, traduce Gebilde por forma (cf. K. Bühler, Teoría del lenguaje, Alianza Editorial, Madrid, 1979 [1 $1^{a}$ edición en alemán, 1934], p. 69).

37. Preséntase un profundo repaso destes termos en E. Coseriu: «Sistema, norma y habla» en E. Coseriu, Teoría del lenguaje y lingüística general. Cinco estudios, Gredos, Madrid, 1962, pp. 11-113.

38. Claramente perceptible en Humboldt, polo seu recurso á terminoloxía grega.

39. E. Coseriu, «Determinación y entorno. Dos problemas de una lingüística del hablar», Romanistisches Jahrbuch, VII, 1955-1956, pp. 29-54; e, posteriomente, en E. Coseriu, Teoría del lenguaje..., op. cit., pp. 282-323, por onde cito. 
aristotélicas e sinala que, na realidade, a concepción aristotélica é máis complexa, o cal talvez permite resolver de forma coherente a dificultade de interpretación. Aristóteles distingue -di Coseriu ${ }^{40}-$ entre as actividades como tales ( $\boldsymbol{i} \boldsymbol{\alpha} \boldsymbol{\tau}^{\prime}$ ह่vé $\rho \boldsymbol{\gamma} \varepsilon \boldsymbol{\imath} \boldsymbol{\alpha} \boldsymbol{v}$ ), as actividades en potencia $(\boldsymbol{\kappa} \boldsymbol{\alpha} \boldsymbol{\alpha} \dot{\boldsymbol{\alpha}} \boldsymbol{\delta} \boldsymbol{v} \boldsymbol{v} \boldsymbol{\alpha} \boldsymbol{\mu \imath \boldsymbol { v }})$ e as actividades realizadas nos produtos ( $\boldsymbol{i} \alpha \tau^{\prime}$ ép $\left.\rho \gamma \boldsymbol{o v}\right)$. Coseriu combina a tripartición aristotélica con outra tricotomía, fundamental para a súa concepción lingüística: a distinción entre o nivel universal do falar en xeral, o nivel histórico das linguas e o nivel individual do falar ${ }^{41}$. Chega, deste xeito, ao seguinte esquema de nove campos ${ }^{42}$ :

\begin{tabular}{|c|c|c|c|}
\hline & 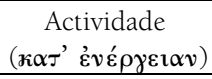 & $\begin{array}{l}\text { Saber (competencia) } \\
\left(\boldsymbol{\varkappa} \alpha \boldsymbol{\tau}^{\prime} \delta \delta^{\prime} \boldsymbol{v} \boldsymbol{\mu} \boldsymbol{\mu} \boldsymbol{v}\right)\end{array}$ & $\begin{array}{l}\text { Produto (obra) } \\
\left(\varkappa \alpha \tau^{\prime} \text { '̌́ } \rho \gamma \mathbf{o v}\right)\end{array}$ \\
\hline $\begin{array}{l}\text { Plano universal: } \\
\text { falar en xeral }\end{array}$ & falar en xeral & saber elocutivo & $\begin{array}{l}\text { totalidade das } \\
\text { manifestacións }\end{array}$ \\
\hline $\begin{array}{l}\text { Plano histórico: } \\
\text { lingua concreta }\end{array}$ & lingua particular & saber idiomático & $\begin{array}{c}\text { (lingua particular } \\
\text { abstracta) }\end{array}$ \\
\hline $\begin{array}{l}\text { Plano individual: } \\
\text { discurso (texto) }\end{array}$ & discurso & saber expresivo & texto \\
\hline
\end{tabular}

40. E. Coseriu, «Determinación y entorno. Dos problemas...», op. cit., p. 286.

41. Anos máis tarde Coseriu afirma que considera esa distinción tan simple, pero tan fundamental (con todas as súas consecuencias), a súa maior contribución á lingüística xeral (cf. E. Coseriu, «Linguistic Competence: What is it Really? The Presidential Address of the Modern Humanities Research Association», The Modern Language Review, 80/4, 1985, pp. XXV-XXXV). En xeral, pódese dicir que é unha das características fundamentais da teoría da linguaxe de Coseriu a descrición dos feitos lingüísticos por medio de tricotomías (por exemplo, os tres niveis do falar-sistema, norma e fala-, sincronía, diacronía e historia, as tres dimensións variacionais, as tres clases de dialectos etc.) opostas ás dicotomías tradicionais do século $\mathrm{xx}$, atribuíbles en gran parte a Saussure (cf. J. Kabatek: «Eugenio Coseriu: Memoria, lógica y fuerza de trabajo», en M. L. Calero e F. Rivera Cárdenas, eds., Estudios lingüísticos y literarios in memoriam Eugenio Coseriu, Universidad de Córdoba, Córdoba, 2004, pp. 43-50). Incluso podería dicirse que na lingüística do século xx predominan tres paradigmas: un paradigma dicotómico-categórico (Saussure, a maior parte das escolas estruturalistas, Chomsky); un paradigma anti-aristotélico, predominante na lingüística chamada cognitiva, que nega a existencia real das categorías; un paradigma tricotómico-categórico, que non nega a continuidade de certos fenómenos, pero si separa o nivel do continuo do nivel da categorización. Este terceiro paradigma débeselle a Coseriu e á súa escola, pero vemos que xa se atopa, en certo modo, en Aristóteles e, partindo de aí, en Amor Ruibal.

42. E. Coseriu, Competencia lingüistica. Elementos de la teoría del hablar, Gredos, Madrid, 1992 [orixinal en alemán, 1988; tradución ao español por F. Meno Blanco] p. 88. 
A clasificación é máis complexa ca a de Bühler, pero tamén máis coherente; nela entra tanto o individual como o social, así como tamén o universal; ademais, non se limita aos dous aspectos de produción e produto, senón que inclúe tamén a potencia de produción.

Da insuficiencia do pensamento dicotómico tamén se decata Amor Ruibal e, así como o faría Coseriu medio século máis tarde, el tamén propón -supostamente con referencia a Aristótelesunha tripartición que corresponde á dimensión horizontal do esquema coseriano, sendo a única diferenza a elusión do terceiro dos termos aristotélicos. Amor Ruibal limítase a citar os dous termos de Humboldt, aínda que distingue entre dúas évé $\rho \gamma \varepsilon \imath \alpha \imath: a$ primeira, antes citada, é a actividade individual; a segunda non é outra, de feito, ca a $\delta \dot{v} v \alpha \mu \imath$ aristotélica:

Considerada en su realidad subjetiva concreta, la lengua es también una actividad -una energía asociada a nuestro ser psicológico y latente como las ideas y conceptos que informan sus vocábulos en reposo, cuyo conjunto reviste el carácter de instrumento psíquico y mnemotécnico al servicio del hombre que le da a su arbitrio realidad objetiva al hablar ${ }^{43}$.

A definición dada aquí é, pois, comparable á da competencia lingüística de Coseriu, xa que tamén inclúe o aspecto da linguaxe $\boldsymbol{i} \boldsymbol{\alpha} \tau \dot{\alpha} \delta \dot{v} \boldsymbol{v} \boldsymbol{\alpha} \mu \boldsymbol{\imath} \boldsymbol{v}$ de Aristóteles, distinguindo entre unha actividade indi-

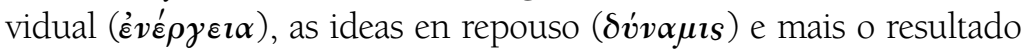

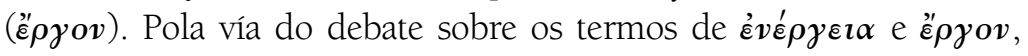
Amor Ruibal chega á súa propia definición da linguaxe: «Un sistema de sonidos articulados para la transmisión de nuestros conceptos y sensaciones» ${ }^{44}$. É unha definición semellante á da langue no sentido de Saussure, xa que nela domina a idea da sistematicidade. Pero non abonda coa perspectiva da lingua: a esta hai que engadirlle outra, a dos falantes, para quen falar é «manifesta[r] [...] los conceptos y sensaciones mediante sonidos articulados reducibles á sistema» ${ }^{45}$.

43. PFFC II, p. 103.

44. PFFC II, p. 121.

45. PFFC II, p. 121. 
Ruibal recoñece, pois, por un lado, o carácter social da langue como sistema, mais, por outro lado, non reduce, como o fará Saussure, a lingüística a unha lingüística da langue. Para el queda sen tocar -como para Humboldt, a quen cita neste contexto- a primordialidade da actividade individual. Di Ruibal:

El lenguaje así considerado, es siempre de origen personalísimo, cualquiera que sea el medio de donde se ha tomado, y lo forma cada individuo en el momento en que habla; por eso decimos de tales sonidos que son reducibles a sistema, fijándonos en su principio genético, único atendible en la definición aludida. "Die Sprache, dice bien Humboldt ([Über die] Versch[iedenheit] d[es] menschl[ichen] Sprachb [aues] ed. [Heymann] Steinthal [1823-1899] ${ }^{46}$ ), in ihrem wirklichen Wesen aufgefasst, ist etwas beständig und in jedem Augenblicke Vorübergehendes... Ihre wahre Definition kann daher nur eine genetische sein. Sie ist nämlich die sich ewig wiederholende Arbeit des Geistes, den artikulierten Laut zum Ausdruck des Gedankens fähig zu machen" ${ }^{\prime \prime 7}$.

Sen deixar de recoñecer a importancia da diferenciación saussuriana entre a lingua como feito social e a parte individual, Amor Ruibal insiste sobre unha lingüística que parte do individuo, dado que a actividade do falar é anterior á lingua. Para Saussure, en cambio: «il faut se placer de prime abord sur le terrain de la langue et la prendre pour norme de toutes les autres manifestations du langage ${ }^{48}$. Case medio século despois, será precisamente a inversión desa doutrina o que inicie unha visión nova da lingüística e permita darlle paso a unha visión completa da actividade lingüística, que inclúe disciplinas alén da lingüística da langue, como a pragmática ou a lingüística de texto; así, en «Determinación y entorno», Coseriu di que «en lugar de colocarse en el terreno de la

46. Amor Ruibal debe de estar a referirse a unha reprodución do Über die Verschiedenheit recollida na seguinte antoloxía de traballos humboldtianos de teoría da linguaxe: Die sprachphilosophischen Werke Wilhelm von Humboldt, hrsg. und erkl. von Dr. H. Steinthal, Dümmler, Berlín, 1884.

47. PFFC pp. 121 n. 1.

48. F. de Saussure, Cours..., op. cit., p. 25. 
lengua, 'hay que colocarse desde el primer momento en el terreno del hablar y tomarlo como norma de todas las otras manifestaciones del lenguaje (inclusive de la «lengua)' ${ }^{49}$.

Tanto Amor Ruibal como Coseriu parten de Humboldt para as súas distincións, mais sen confiar en Humboldt exclusivamente, senón remontando ata a tradición aristotélica. Nesta profunda referencia á tradición do pensamento lingüístico atopan solucións que van alén do que sería a concepción dominante ao longo do século xx: a saussuriana limitación a unha lingüística da langue.

\section{LINGUA FALADA/LINGUA ESCRITA}

O recurso á tradición clásica -non como mero argumento de autoridade, senón como referencia real, moitas veces implícitaé perceptible ao longo de toda a obra lingüística de Amor Ruibal. Vexamos outro exemplo. Hoxe en día é común atribuír a Ferdinand de Saussure ou a Leonard Bloomfield (1887-1949) a tese de que a lingua falada e a lingua escrita son dous sistemas distintos e a de que a segunda deriva da primeira. Así, por exemplo, di Bloomfield: «Writing is not language but merely a way of recording language by means of visible marks» ${ }^{50}$. E xa antes dixera Saussure: «Langue et écriture sont deux systèmes de signes distincts; l'unique raison d'être du second est de représenter le premier $»^{51}$. En Amor Ruibal atopamos a mesma idea, algúns anos antes do Cours de Saussure:

El lenguaje escrito no es propiamente más que un signo de la palabra hablada, que ya no existe, y un instrumento de reversión mediante el cual[,] y dándole su valor fonético, podemos volver sobre aquella palabra y hacerla venir a la existencia formando así de nuevo el idioma en nuestros labios ${ }^{52}$.

Máis adiante, Amor Ruibal di o seguinte sobre a relación entre o son e a grafía: «El sonido [...] es independiente de la idea, y

49. E. Coseriu, «Determinación y entorno. Dos problemas...», op. cit., p. 286.

50. L. Bloomfield, Language, Henry Holt \& Co., Nova York, p. 21.

51. F. de Saussure, Cours..., op. cit., p. 45.

52. PFFC II, p. 104. 
la escritura es independiente del sonido, como representación evidentemente convencional $\aleph^{53}$. Este principio de dupla arbitrariedade recorda a argumentación aristotélica, segundo a cal o que está contido na voz (isto é, o fonema) é nota ou base de evocación do signo lingüístico ${ }^{54}$. A escrita -apunta o noso autor- só entra en relación coa fala por obra dunha convención arbitraria establecida pola cultura humana: «[E]l sonido oral y la escritura son dos órdenes de signos totalmente diversos e independientes, que sólo la acción refleja del trabajo intelectual humano ha conseguido aproximar» $\aleph^{55}$.

Aquí tamén vemos o fondo clásico común que caracteriza tanto a obra de Ruibal como a doutrina de Humboldt. Humboldt insiste sobre a esencia da actividade lingüística e avisa das miraxes que pode provocar a escrita. Na escrita semella que a lingua posúe unha existencia exteriorizada obxectiva, pero, como di Humboldt, esa existencia é só virtual e reviste un certo carácter de momificación ${ }^{56}$. Só cando se revitaliza a lingua escrita, só cando se volve crear na mente humana, só entón se volve real:

Denn sie [scil. a lingua] hat nirgends, auch in der Schrift nicht, eine bleibende Stätte, ihr gleichsam todter Theil muss immer im Denken aufs neue erzeugt werden, lebendig in Rede oder Verständniss, und folglich ganz in das Subject übergehen ${ }^{57}$.

\section{FRANZ BOPP E WILHELM VON HUMBOLDT}

A obra lingüística de Amor Ruibal tivo un éxito reducido por múltiples razóns. Unha delas foi a falta dun ambiente que soubese apreciar a súa calidade; porén, talvez se lle poida imputar unha parte

53. PFFC II, p. 151.

54. «Sunt ergo ea quae sunt in voce earum quae sunt in anima passionum nota» (De interpretatione, 1, 1; Aristóteles, Dialectica [tradución ao latín por S. Boecio], apud Hectorem Pernet, Lyon, 1554, p. 69).

55. PFFC II, p. 151.

56. «Selbst ihre Erhaltung durch die Schrift ist immer nur eine unvollständige, mumienartige Aufbewahrung» (W. von Humboldt, Gesammelte Schriften..., op. cit., p. 41).

57. W. von Humboldt, Gesammelte Schriften..., op. cit., p. 63. 
da responsabilidade ao seu estilo, por veces algo seco, que non axudaba a asimilar unha materia que era estraña para os españois da época. Aínda así, xa se observou en repetidas ocasións que Amor Ruibal, nalgúns momentos clave dos seus principais traballos de tema lingüístico, cambia de ton e introduce certos elementos de emoción, certa expresividade (case poderiamos falar de paixón). Sucede isto, por exemplo, no comezo da segunda parte de Los problemas fundamentales de la filología comparada. Nesas páxinas ${ }^{58}$, que se centran no estudo da índole e a repercusión da obra de Lorenzo Hervás y Panduro (1735-1809) e Franz Bopp, o lector áchase ante un tratamento diferente da materia. En ambos os casos, don Ángel comeza cunha sobria caracterización inicial de valor xeral, mais o estilo cambia decontado e inclínase cara ao entusiasmo. Sobre Hervás, figura clave na historia da lingüística moderna, Amor Ruibal fala cun exacerbado patriotismo; el sostén que Hervás é «[e]l iniciador de la ciencia glotológica», e quere «reclamar para el sacerdote español y para la patria este timbre de gloria $\aleph^{59}$.

O xeito de presentar a Franz Bopp é semellante. Para que un individuo poida aparecer realmente como alguén que cambiou o mundo, é apropiado pintar primeiro un panorama da situación previo á súa chegada e identificar despois todo o que mudou tras a súa aparición; por fin chega Bopp e todo cambia:

Tal era el estado de cosas cuando apareció Bopp. Era menester para llevar a feliz término la empresa de la comparación lingüística indo-europea un vasto talento que a la condición del saber reuniese la de una voluntad firme[,] capaz de superar las dificultades que ofrece siempre toda innovación, un carácter independiente que[,] prescindiendo de convencionalismos antiguos[,] impusiese la dictadura en materias lingüísticas; y en Francisco Bopp juntábanse por modo singular todas estas condiciones ${ }^{60}$.

Nos apuntamentos bio-bibliográficos que sobre Bopp nos ofrece Amor Ruibal, chama a atención, non só o evidente ton de

58. PFFC II, pp. 1-45.

59. PFFC II, p. 2.

60. PFFC II, p. 26. 
admiración (pouco frecuente no noso autor, que se revela xeralmente bastante crítico con todos), senón tamén, no que segue, a inclusión de toda unha serie de informacións cuxa procedencia exacta descoñecemos. Na procura das fontes cabería pensar, en primeiro lugar, en Salomon Lefmann (1831-1912)61. Mais ocorre que a grande obra de Lefmann non consta no catálogo da biblioteca de don Ángel. Ademais, no texto de Los problemas fundamentales aparecen informacións non contrastadas co que se recolle no de Lefmann, como pode ser o dato do contacto con Humboldt en Inglaterra ${ }^{62}$; por outra parte, o autor alemán achega moita información (detallada e de certa importancia) que non se atopa nas páxinas que escribiu don Ángel. Non puidemos identificar con absoluta seguridade a fonte principal de que usou o noso autor, pero hai que sinalar que na primeira versión do texto (e no que toca á biografía de Bopp coinciden, agás pequenos detalles, o texto da «Introducción a la ciencia del lenguaje» ${ }^{63}$ e o de Los problemas fundamentales de la filología comparada) hai algúns topónimos en versión francesa ou con erratas que apuntan a que Ruibal non manexaba un texto alemán, senón máis ben un texto francés.

A admiración por Bopp como verdadeiro innovador no ámbito da filoloxía comparada móstrase ao longo de toda a obra. Non é só a creación do método histórico-comparativo o que se gaba, senón tamén o mérito de «formular una doctrina general ${ }^{64}$ e de formar un sistema metodolóxico completo apoiado en feitos empíricos. Sobre estes, Ruibal revélase en parte escéptico, pero o conxunto do pensamento de Bopp parécelle «monumento perdurable, y obra que no sólo históricamente[,] en cuanto abre los anales de la Ciencia del Lenguaje, sino también por su valor intrínseco como tesoro lingüístico, habrá de ser mirada con respeto en todo tiempo $»^{65}$.

61. S. Lefmann, Franz Bopp, sein Leben und seine Wissenschaft, Georg Reimer, Berlín, 3 vols., 1891- 1897. Cf. tamén supra n. 4.

62. Cf. PFFC II, p. 29.

63. Trátase -recordémolo- do extensísimo prefacio que Amor Ruibal escribiu para a súa tradución dos Principes de Regnaud (cf. supra n. 12).

64. PFFC II, p. 43.

65. PFFC II, p. 43. 
Neste contexto, é interesante a comparación que Ruibal establece entre Bopp e Humboldt. Por un lado, afirma que en Bopp non hai coherencia teórica e que as súas posturas no plano da teoría van cambiando segundo o material empírico que manexa... cousa que, emporiso, non parece molestar demasiado a Ruibal:

Bopp admite leyes sin excepción en los cambios fonéticos, y al mismo tiempo reconoce que las lenguas pueden emanciparse de las normas establecidas; cree unas veces que las leyes del lenguaje «son tan inseguras como las orillas de los ríos y de los mares» ${ }^{66}$, y otras se fía en absoluto de su estabilidad inquebrantable ${ }^{67}$.

Por outro lado, de Humboldt di, en cambio, que é coherente nas súas explicacións universais, pero menos acertado nalgún que outro xuízo sobre feitos empíricos, e a Amor Ruibal importáballe moito a exactitude dos datos. Non atopamos unha gabanza de Humboldt comparable á de Bopp; incluso hai palabras que limitan o valor de Humboldt, falando de maneira indirecta e xeral da importancia das persoas e do seu prestixio: «existe una cierta gradación que no siempre puede medirse exactamente por el mayor o menor prestigio de que gozan ${ }^{68}$. Parece que a Ruibal lle molesta a enorme fama e o prestixio do gran político, filósofo e lingüista Humboldt a carón do máis humilde Bopp, a quen os neogramáticos consideraban máis ben superado. Cos neogramáticos, Amor Ruibal tamén amosa certo distanciamento (aínda que, de vivir en Leipzig e non en Santiago, había ser probablemente discípulo deles, dada a súa data de nacemento). Afirma repetidas veces que «es imposible demostrar que las leyes fonéticas sean inmutables y sin excepción ${ }^{69}$ e opón á doutrina da regularidade absoluta o

66. Aínda que Amor Ruibal non o sinale expresamente, aquí está a citar unha sentenza do mesmo Bopp: «Auch suche man in Sprachen keine Gesetze, die festeren Widerstand leisten als die Ufer der Flüsse und Meere» (Vocalismus, oder sprachvergleichende Kritiken, Nicolaische Buchhandlung, Berlín, 1836, p. 15).

67. PFFC II, p. 43.

68. PFFC II, p. 45.

69. PFFC II, p. 92. 
«carácter personalísimo de la palabra» ${ }^{70}$, talvez en alusión a Hugo Schuchardt (1842-1927). Ao mesmo tempo, don Ángel está cheo de admiración pola consecuente metodoloxía dos neogramáticos e presenta, en dúas páxinas ${ }^{71}$, un precioso e clarísimo resumo dos seus principios. E escribe, a modo de conclusión: «[L]os neogramáticos representan la síntesis del verdadero espíritu de investigación lingüística, en cuanto se intenta realizar sistemáticamente el estudio psicológico y fisiológico del lenguaje» ${ }^{72}$.

Neste contexto tamén escribe a sentenza que aparecía como lema baixo o título deste traballo: «solo lo que es normal y reducible á sistema puede estudiarse científicamente» ${ }^{73}$. Ao lela comprendemos que no fondo é natural que o neogramático Saussure desenvolvese unha lingüística de sistema. Era, en certa maneira, a continuación consecuente de certos principios dos neogramáticos, a ampliación a unha proxección sincrónica dos principios do feito social e do psicoloxismo, xa presentes na obra de Hermann Osthoff (1847-1909), de Karl Brugmann (1849-1919), de Hermann Paul (1846-1921), de Georg von der Gabelentz (1840-1893) e de Wilhelm Scherer (1841-1886), e tamén na de Humboldt, sobre quen o noso autor observa que «reconocía el carácter psíquico de la palabra» ${ }^{74}$.

É sorprendente comprobar como se move Amor Ruibal entre as posturas antagónicas, sempre de acordo co criterio da interpretación simpatética (é dicir, unha interpretación desde dentro), recoñecendo méritos e criticando onde lle parece necesario,

70. PFFC II, p. 91.

71. PFFC II, pp. 78-79.

72. PFFC II, p. 80.

73. PFFC II, p. 81. Estas palabras posúen un certo sabor neogramático. Evocan, en efecto, unhas célebres observacións de August Leskien (1840-1916) acerca da imposibilidade de someter a tratamento científico unha orde de fenómenos que se produzan caotica, imprediciblemente, sen orde nin concerto: «Lässt man beleibige, zufällige, untereinander in keinen Zusammenhang zu bringende Abweichengen zu, so erklärt man im Grunde damit, dass das Object der Untersuchung, die Sprache, der wissenschaftlichen Erkenntnis nich zugänglich ist» (Die Declination im Slavisch-Litauischen und Germanischen, Hirzel, Leipzig, 1876, p. XXVIII).

74. PFFC II, p. 104. 
poñendo claros límites onde o xulga oportuno. Así, oponse a calquera forma de misticismo lingüístico, pero salva a Bopp e a Humboldt cando somete a xuízo a metáfora (común no século XIX) da lingua como organismo; no caso destes pioneiros alemáns, considera que a metáfora en cuestión está por completo xustificada: «el lenguaje [...] puede, sin duda alguna, denominarse organismo» ${ }^{75}$. Ao mesmo tempo, don Ángel critica moi duramente as teorías de August Schleicher (1821-1868), o seu «darwinismo», os seus «erróneos conceptos», as súas «exageraciones insostenibles» ${ }^{76}$. Segundo Amor Ruibal, o núcleo do pensamento lingüístico de Schleicher está constituido por ideas de Bopp mal dixeridas e completadas con algúns dislates de invención propia. O noso autor é autoritario e paternal; é capaz de gabar, por un lado, pero, por outro lado, tamén de ser ben duro cos que defenden teses que el estima aberrantes, como a do «simbolismo significativo [de los sonidos]», que tacha de «fundamentalmente fals[a] y creación de pura fantasía» ${ }^{77}$, e de «cábala lingüística» ${ }^{78}$; É brillante a súa argumentación conxunta en contra do darwinismo e do fonosimbolismo, que se funda en que ambos son modelos teleolóxicos, «antitéticos en la forma», si, mais «análogos en el fondo», orientados cara a unha suposta mellora, nun caso, e cara á decadencia, no outro:

En el fondo llevan las aludidas doctrinas una manera de darwinismo invertido aplicado a las lenguas; lo que en la evolución darwiniana se efectúa en línea ascendente y progresiva, verifícase aquí en línea regresiva y descendente; la naturaleza inconsciente que en el darwinismo crece y se perfecciona multiplicándose en especies físicas nuevas, decrece al tratarse de la palabra, degenerando el lenguaje primero en formas lingüísticas antes no conocidas ${ }^{79}$.

75. PFFC II, p. 105.

76. PFFC II, p. 50

77. PFFC II, p. 144.

78. PFFC II, p. 146.

79. PFFC II, p. 147. 
Colíxese nestas observacións unha gran capacidade para a combinación e síntese de diferentes ideas, para a redución dunha morea de teses e de influencias diversas a un sistema unitario de pensamento, trazo característico do estilo argumentativo de Amor Ruibal.

\section{CONCLUSIÓN}

Como vimos de dicir, estas breves observacións sobre algunhas das ideas lingüísticas de Amor Ruibal axúdannos a nos formar unha idea da súa maneira de traballar e de argüír. No plano da teorización, Amor Ruibal reúne unha sólida base de formación filosófica clásica (sobre todo, aristotélica), un coñecemento amplo dos escritos de filoloxía e de lingüística da súa época e unha extraordinaria capacidade para combinar, analizar e sintetizar. Este terceiro nivel, o da combinación e sistematización, pecha o círculo co primeiro, tamén de síntese e de principios fundamentais. Os tres niveis teóricos combínanse co afán de precisión e coherencia metodolóxica e coa exactitude e exhaustividade no manexo dos datos empíricos. Don Ángel é, en fin, un precursor para a lingüística española, un investigador que merece que se lle asigne o posto adecuado no panorama da historia global da disciplina. Descubrirase aínda, con bastante probabilidade, que o seu influxo na evolución ulterior da lingüística en España foi maior do que se pensa; pero moito máis importante será descubrir cales das ideas e das argumentacións deste «legislador primero de la lingüística, universal maestro de la gramática comparada» ${ }^{80}$ seguen vixentes na actualidade.

80. Cualificativos que Amor Ruibal lle aplicou a Lorenzo Hervás y Panduro (PFFC II, p. 2) e que nós, pola nosa parte, podemos aplicarlle agora a el. 